\title{
Corrupting the Youth: Should Parents Feed their Children Meat?
}

\author{
Daniel Butt ${ }^{1}$ (iD \\ Accepted: 6 August 2021 / Published online: 24 August 2021 \\ (C) The Author(s) 2021
}

\begin{abstract}
This article is concerned with choices that parents or guardians make about the food they give to their children. Those with primary responsibility for the care of young children determine the set of foods that their children eat and have a significant impact on children's subsequent dietary choices, both in later childhood and in adulthood. I argue that parents have a morally significant reason not to feed meat to their children, which stems from their fiduciary responsibility for the child's moral development. This should, at a minimum, be factored into parental decisions about their children's diet. In the absence of compelling countervailing reasons, it will mean that parents should not, in an all-things-considered sense, feed meat to their children. This claim does not rely upon the obviously contentious claim that it is morally wrong to eat meat. Instead, the fact that children, when adults, may reasonably themselves come to believe that consuming meat is wrong gives parents morally compelling reasons to avoid acting in ways which may have the predictable consequence of corrupting the moral character of those for whom they are responsible.
\end{abstract}

Keywords Vegetarianism $\cdot$ Corruption $\cdot$ Children $\cdot$ Parents $\cdot$ Veganism

\section{Introduction}

This article is concerned with choices that parents or guardians make about the food they give to their children. Those with primary responsibility for the care of young children determine the set of foods that their children eat and have a significant impact on children's subsequent dietary choices, both in later childhood and in adulthood. I argue that parents have a morally significant reason not to feed meat to their children which stems from their fiduciary responsibility for the child's moral development. This should, at a minimum, be factored into parental

Daniel Butt

daniel.butt@politics.ox.ac.uk

1 Balliol College and Department of Politics and International Relations, University of Oxford, Oxford, UK 
decisions about their children's diet. In the absence of compelling countervailing reasons, it will mean that parents should not, in an all-things-considered sense, feed meat to their children.

Importantly, this argument is intended to stand independently of the claim that it is morally wrong to eat meat. The key idea here is that children may come to endorse some variant of ethical vegetarianism, which holds that eating meat, or more broadly acting in a way that leads to increased demand for meat, is morally wrong. ${ }^{1}$ If they do come to this conclusion, and if they have eaten meat up to this point, it follows that their parents' avoidable actions in feeding them meat are likely to have had a corrupting effect on their moral integrity. This is bad, as parents possess what Harry Brighouse and Adam Swift have described as a "fiduciary responsibility" for the moral development of their children (Brighouse and Swift 2006). My conclusion is that many people in affluent societies, who have significant discretion over the food they choose to buy and prepare, violate their duties to their children if they elect to give them meat prior to the point where their children are morally responsible for their own choices. From this perspective, it would generally be better if parents withheld meat from children until they are old enough to make their own decisions about consumption. At the least, it should be acknowledged that there are moral costs to choosing to give meat to a child.

This conclusion is not generally asserted in either philosophical or policy contexts. ${ }^{2}$ Insofar as questions of parental choices about children's diet are raised, they normally concern whether it is permissible for vegetarian parents to withhold meat from their children. Legislation proposed in Italy in 2016 would have seen parents prosecuted for raising children on vegan diets and for encouraging other "reckless and dangerous eating behaviour" (Hunt 2016); previously an Italian court compelled a vegetarian mother to prepare meat for her son at least weekly following a complaint from the son's divorced father (The Local, 2015). Both cases were seemingly motivated by concern about the dietary effects of veganism or vegetarianism on child development, but vegetarian parents who do not feed their children meat are also well accustomed to both friendly and less than friendly accusations that they are imposing their own values upon their children, and so violating what Joel Feinberg described as a child's "right to

\footnotetext{
${ }^{1}$ I take it that the most common real-world version of ethical vegetarianism holds that it is morally wrong to eat meat. In the theoretical literature, some, but not all, ethical vegetarians (and vegans) argue that it is not the physical act of eating meat, but the production and /or purchase of meat which is wrong, since it is the latter which is most directly linked to causing harm to animals. While eating meat will often also play a causal role, by leading to further purchase and further production, it does not do so necessarily (thus it may not be wrong to eat, for example, accidentally produced roadkill - see Milburn 2020, 2021). Given that in the vast majority of cases in affluent societies the meat that is consumed is in fact purchased, there is generally a straightforward link between consumption, purchasing, and ultimately production. It is the consumption of this kind of meat with which the article is concerned. Thus references to eating meat being wrong should be understood to include both the belief that eating meat is wrong per se, and that it is bad when doing so leads to purchasing and production that harms animals.

${ }^{2}$ The only argument I have found in the literature that approximates my own is made by Carlo Alvaro, in relation to the recent debate as to whether there should be compromise between a vegan and a non-vegan parent as to raising their children as vegan. (on this debate, see Alvaro 2020, Hunt 2019b and 2021, Milburn 2020 and 2021). He argues that given that the consumption of animal products is a morally controversial issue, parents ought not "to make their children bear such moral responsibilities. Consider that children may in time resent their parents in the event that they will grow up to be a convicted vegan. How odd would that be for a child: dad is a vegan, and yet he made a compromise with mom about feeding me animal products?... Consequently, in my view the best policy to observe is to raise children as vegans, paying particular attention to their health (if that is even an issue). When they reach moral maturity, they will have options to continue to be vegans or to consume animal products." (2020: 93) Alvaro characterises this as an issue of the vegan parent's moral integrity. By contrast, my argument applies regardless of whether either parent subscribes to ethical vegetarianism or veganism. I address veganism specifically in section 6 . I am grateful to an anonymous referee for drawing this article to my attention. More generally, the ethics of raising children as vegetarian or vegan is strikingly underdiscussed, this recent literature on veganism and parental compromise notwithstanding. (For discussion, see Milburn 2020: 2.)
} 
an open future" (Feinberg 1980; Mills 2003). However, others have argued that there are compelling grounds for the claim that it is justifiable for vegetarian parents not to give meat to their children, so long as they ensure that doing so does not compromise the nutritional well-being of the children in question (Sherratt 2007). The question is usually framed in terms of whether it is permissible for a parent who is an ethical vegetarian either to withhold meat from their children, or, more strongly, to seek to encourage their children to adopt ethical vegetarianism. So, for example, Matthew Clayton notes that if eating meat is indeed unjust, "parents would not be permitted to feed their children meat, just as they are not permitted to steal from others" (Clayton 2006: 109). My question in this article, however, is different. I am explicitly concerned with the narrow issue of including meat in children's diet, and say nothing of the propriety or otherwise of seeking to persuade children that eating meat is wrong. While I do believe that vegetarian parents do not wrong their children by withholding meat from them, my distinctive claim is to argue more strongly that parents in general, whether vegetarian or not, have a morally significant reason not to give meat to their children. Critically, this reason does not depend on the truth of ethical vegetarianism.

This is an unusual position. Sherratt, for example, explicitly denies that she is seeking to argue that "a parent should raise their child as vegetarian", instead arguing "merely that it is not wrong for her to do so" (a position that she nonetheless describes as a "controversial claim") (Sherratt 2007: 426). Even writers who place substantial restrictions on parental conduct in defence of the autonomous development of children have not maintained that a concern for the child's autonomy requires a non-meat diet. In fact, Andrew Mason presents such a conclusion as a reductio ad absurdum of the application of Matthew Clayton's "precondition view of the right to autonomy" to religious instruction, asking:

Why should we suppose that religious instruction violates the child's right to autonomy? If the point is just that it involves imparting a particular 'comprehensive' conception of the good, then respect for autonomy, so understood, would be highly restrictive. It would seem to rule out cultivating in children virtues such as kindness and generosity, or a particular aesthetic sensitivity, and prohibit feeding a child fish, meat or even dairy products (to the extent that this presupposes the permissibility of exploiting fish and animals for this purpose). (Mason 2000: 164).

Clayton's response accepts that certain ways of seeking to affect the dietary decisions of children might be unacceptable, but he strikingly does not go so far as to argue that a respect for children's autonomy means they should not be fed meat:

[T] he precondition conception rules out certain kinds of intentional conduct, not particular kinds of behaviour or outcomes... If parents provide their children with a balanced diet, expose them to a variety of different conceptions of eating, and display a sensitivity to the emerging gastronomic conceptions of their children, then on the precondition view they do not violate their autonomy. They would violate their autonomy if they fed meat to their children with the aim of cultivating another meat eater... Two children can have the same thing happen to them - they are fed meat, for example — but, nevertheless, the motivation of the parents can be markedly different in a way that is relevant to the children's autonomy. One parent might be motivated solely by the aim of providing a balanced diet while another might aim to create carnivores. (Clayton 2006: 109-110). 
If, following Clayton, we understand the interest of the child in terms of their autonomous development, then the conclusion that justice requires a balanced diet with exposure to a range of different foods including meat seems, at first glance, to be reasonable. The child is brought up in a way which allows them to make informed choices about their diet when old enough to do so: they can draw on a range of experiences and have not been inculcated with a belief that only one approach to eating is permissible. In what follows, I argue that this position fails to appreciate both the particular character of ethical vegetarianism and the nature of a parent's obligation to refrain from having a corrupting effect on the moral integrity of their children.

\section{Starting Assumptions}

The substantive argument of the article rests upon three assumptions:

a) It is feasible to raise a child on a vegetarian diet without posing any significant threat to their health.

b) There is a significant chance that a given child will come to believe that eating meat is morally problematic, even if they are not brought up as an ethical vegetarian.

c) Ethical vegetarianism does not cause harm to others, and should be viewed as reasonable by non-vegetarians.

I do not defend (a) at length. I understand a vegetarian diet here as one that does not include the flesh of either wild or farmed animals, including fish. It may, however, contain other animal products which would be excluded by a vegan diet, such as eggs or dairy foods (I discuss veganism specifically in section 6 below). There is consistent scientific evidence that vegetarian diets are not harmful if children consume balanced diets with sufficient levels of protein and essential amino acids, fatty acids, vitamins, and minerals (Amit 2010). Parents who do not give meat to children need to pay attention to what their children consume and ensure they eat an appropriate range of foods, but if so, they neither cause nor risk harm to their children's development. A recent study of the nutritional status of vegetarian children concludes that:

According to long-term experience and opinions of expert nutritionists and pediatricians from all over the world, well-planned vegetarian diets are appropriate for all stages of childhood and adolescence, and they are comparable in this regard to conventional diets... When vegetarian children are fed a well-balanced diet, they develop well. It is often observed that vegetarian children have better nutritional status, and their diet appears more aligned with guidelines than is the case observed in omnivores. (Gorczyca 2017: 543).

It should be noted that this conclusion has at times been disputed. Kathryn Paxton George, for example, has argued that vegan and, to some degree, vegetarian diets are only straightforwardly healthy for those in relatively privileged positions with particular advantages of education, healthcare, and access to resources (George 1990, 2000); though others have pushed back forcefully at her reading of the nutrition literature (see for example Lucas 2005: 161). (George argues that "parents are probably under an obligation to include some meat and animal products in the diet of their children" (1990: 176), but also argues that those not required to be vegetarian are "permitted to eat only enough to ensure adequate nutrition and health, with a reasonable margin for safety" (178). If this position is accepted, then the 
argument of this article can simply be applied to any surplus consumption of meat above this margin.) I accept that the evidence relating to children and veganism is less clear than that relating to vegetarianism, and at least that it is harder for parents to ensure the nutritional well-being of their children if they are raised on a vegan diet (Hunt 2019a). I return to this question in section 6 below.

In (b), and generally, I am particularly concerned with objections to eating meat that hold that eating animals is wrong because it involves animals being treated in ways that they should not be treated. This kind of moral reason not to eat meat can be differentiated from reasons which are focussed not on the treatment of animals themselves but on the broader environmental impact of the meat industry, owing, for example, to the carbon emissions associated with the rearing of livestock (see McMichael et al. 2007), as well as other aesthetic or health-based reasons, and at least some reasons rooted in religious belief. My assumption is that, in many countries, there is a reasonable chance that a child will come, either in childhood or adulthood, to believe that eating meat is wrong. It is hard to be precise as to how likely this is. Recent opinion polling in the US has identified the percentage of the population that considers itself to be vegetarian at 5\%, with a further $3 \%$ that describes itself as vegan (Reinart 2018). Similar polling in other Western countries records rates ranging from 1 to $10 \%$, depending on the country in question and the definition of "vegetarian" employed. Rates are much higher in some parts of the world, and it is estimated that $30-42 \%$ of the Indian population are lacto-ovo, ovo, or strict vegetarians (Radak 2014: 280). Obviously not all those who identify as vegetarians or vegans will subscribe to ethical vegetarianism as defined above, while there is also a substantial number of people who think eating meat is wrong, and a larger number still that is uncertain about the propriety of meat-eating, who eat meat regardless. Clearly we cannot know whether future rates of ethical vegetarianism will increase or decrease, so even extrapolating from accurate survey data would not actually tell us the chances of an average child in a particular region becoming a vegetarian. It seems reasonable however, to say that the likelihood of a child becoming a vegetarian in the future is somewhere between $1 \%$ and $10 \%$. It is instructive to compare such figures with those of other possible outcomes for children. For example, in the UK, the figures are broadly comparable to the estimated $2 \%$ of the population that describe themselves as lesbian, gay, or bisexual (Office for National Statistics 2017). While there are no official statistics for the UK trans population, according to Stonewall the "best estimate at the moment is that around 1 per cent of the population might identify as trans, including people who identify as non-binary". ${ }^{3}$ I take it as obvious that these are possible outcomes to which parents and guardians should pay careful attention when they are raising their children. We might also note that the odds of a child becoming a vegetarian are much higher than of adopting specific professions that often guide parental decision-making, including medical doctors (who make up less than $0.5 \%$ of the UK population), lawyers (around $0.25 \%$ ), and professional footballers (rather less than $0.01 \%$ ).

The first part of claim (c) is crucial to my argument, as it maintains that ethical vegetarianism is importantly different from a range of other ethical positions that a child might adopt in contradistinction to those of their parent. Critically, there is an asymmetry between how an ethical vegetarian views a non-vegetarian, and how a non-vegetarian views an ethical vegetarian. Meat-eaters who deny that eating meat is wrong generally think that vegetarians have made a mistake about morality, but it does not follow from this that they are acting immorally. It would be hard to maintain that not eating meat caused wrongful harm to others, just as it

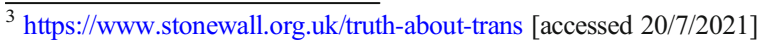


would be hard to accuse someone who just did not like meat and so avoided it of moral wrongdoing (see Sherratt 2007: 426). ${ }^{4}$ If one is an ethical vegetarian, however, one is seemingly committed to the claim that eating meat is morally wrong: indeed some clearly view it as a serious moral wrong. ${ }^{5}$ This differentiates ethical vegetarianism from many other moral issues that provoke heated disagreement, where opponents commonly believe the other side has made a serious moral mistake which renders them complicit in wrongdoing. The second part of (c) builds upon this asymmetry to note that many non-vegetarians view ethical vegetarianism as being reasonable. One can deny that it is wrong to eat animals without thinking that the position is irrational or ridiculous: after all, most people are willing to accept the idea that animal suffering is bad, all other things being equal, and that the treatment of animals raises questions of right and wrong which justify state intervention to prevent certain forms of cruel behaviour. Parents, then, have good reason to view the possibility that their children might become ethical vegetarians with moral equanimity, even if, as will be seen, they may have other concerns relating to the child's well-being or the nature of their relationship. Holding the door open for future vegetarianism does not involve encouraging the possibility that a child might develop in a way that a parent would find morally objectionable, as might be the case, for example, were they to identify with a religion or a political cause that was not shared by the parent. My argument is not intended to be a Trojan horse for any number of other possible moral or religious convictions that children might develop. So while my argument does not hang on the correctness of ethical vegetarianism, it does maintain that meat-eaters should accept that whether or not eating animals is wrong is something about which reasonable, good people can disagree. ${ }^{6}$ I return to the particularity of vegetarianism in this regard in section 5 below.

Parents, then, have a choice as to whether they give their children meat, and make this choice knowing that it is possible that their child will end up believing that eating meat is wrong. A child who did so might, in the eyes of the parent, have made a mistake about morality, but not a mistake which would involve the child in moral wrongdoing: it is just that

\footnotetext{
${ }^{4}$ It is true that a small number of contemporary authors have argued that there is in fact a positive moral duty to eat at least some meat, such as roadkill (Bruckner 2016) or, more broadly, when meat-eating is part of "a past and ongoing practice that benefits animals" (Zangwill 2021). I am dubious that such arguments really do make a plausible case for there being an all-things-considered duty to eat meat (as opposed to a permission or a weak pro tanto duty), but in any case, the key point for this article is that such views are very rare. As Marcus William Hunt writes, "Even if omnivores reject arguments for veganism, vanishingly few omnivores think that eating animals products is morally required or supererogatory, or that there are moral reasons for not raising children as vegans." (2019b: 17-18). I am happy to accept that the reasoning presented here would not apply (at least straightforwardly) to a parent who genuinely believed that it was wrong not to eat meat. But the esoteric nature of the moral belief in question means that parents need not be concerned at the far-fetched prospect that their non-meat eating children might come to believe that their childhood diet was immoral.

${ }^{5}$ As Carlo Alvaro writes in relation to veganism, "ethical vegans approach life and morality in a quasi-religious manner. They are appalled by the capricious ways of meat eaters." (2020: 478). Josh Milburn notes that for many vegans, "veganism... represents not simply something that is morally preferable, or good, or virtuous to do, but something that justice demands of us." (2020: 3 ).

${ }^{6}$ Must ethical vegetarians accept this also? It seems clear that while some may, others do not, and believe that meat eaters are guilty of grievous moral error. Such an ethical vegetarian might accept that a genuine conviction as to the justifiability of eating meat is readily comprehensible, given the widespread social acceptability of meat eating (and indeed the importance of the inculcation of such beliefs in childhood), but still maintain that holding such a view is all-things-considered unreasonable given the import of the moral issues in play, just as it would be unreasonable to endorse slave-holding even in a society where the practice was widespread and generally held to be justifiable. So the picture here need not be of two parties who accept the burdens of judgment and see each other as having come in good faith to a reasonable conclusion. While the meat eater should think this of the vegetarian, the vegetarian need not. The asymmetry here does run deep.
} 
the child would voluntarily forebear from actions the parent views as morally acceptable, though in no way obligatory. This means that giving meat to a child poses a threat to the moral integrity of the child and violates the parent's fiduciary responsibility to care for the child's development. As such, each child who is given meat is wronged, regardless of whether they do go on to endorse a version of ethical vegetarianism. These claims needs further unpacking.

\section{Meat Eating and Moral Corruption}

There are a number of ways in which an individual who endorses ethical vegetarianism may believe that her life has gone less well as a result of being fed meat as a child. Not all relate to the idea of moral corruption at the heart of this article. First, we might note the situation where a person is fed meat prior to the point of moral agency, at which she is responsible for her own choices. Clearly, this does not impugn her moral character, since she is not responsible for her choices at this point, and as a young child may not have made any meaningful dietary choices at all. This is not a situation where she should see herself as being blameworthy for eating meat, and so her moral integrity is not compromised in the way with which this article is principally concerned. Hence, she is not corrupted. Nonetheless, it might still be a source of regret to her to that she was implicated, however unwittingly, in moral wrongdoing: she was a party to, and derived benefit from, what she now views as the avoidable moral wrongdoing of others. Indeed, the physicality of meat consumption means not just that one receives some kind of benefit from eating meat, but that it contributes in a material way to one's bodily growth: it literally becomes part of you, and contributes to the physical development of your mind and body. ${ }^{7}$ (Imagine, for example, the kind of complicated moral regret that an individual would feel if, unknown to her, another agent acted wrongly to obtain a bodily organ which became an irremovable part of her as a result of a transplant operation.) But she has not exercised her agency in a morally problematic way.

Pre-moral responsibility meat consumption may present an ethical vegetarian with a source of regret concerning the choices of her parents, but it cannot be said to corrupt her moral character in any meaningful sense. But children do not stay in a state of moral innocence forever. Things become more complicated when we consider meat consumption after the point where agents are responsible for their actions. The actions of parents may, in such cases, threaten the moral integrity of their children in at least two ways. First, we can consider the case of people who become ethical vegetarians after the point of the development of moral responsibility. If $\mathrm{T}_{1}$ is the point when the individual becomes responsible for their actions, and $\mathrm{T}_{2}$ is when they stop eating meat, it follows that they are guilty of moral wrongdoing between $T_{1}$ and $T_{2}$. They could, and in their eyes should, have chosen to become vegetarians at $T_{1}$, but failed to do so. While their lack of moral agency prior to $T_{1}$ exculpates them, this is not true of their decisions between $T_{1}$ and $T_{2}$. Obviously there is something artificial about the stylised device of treating $\mathrm{T}_{1}$ as an identifiable fixed point of time: in practice, children slowly acquire moral responsibility, developing different aspects of their moral personalities at different times. ${ }^{8}$ Regardless, given that at some point they

\footnotetext{
${ }^{7}$ I owe this point to Helen Stacey.

${ }^{8}$ So Norvin Richards speaks against the idea of treating the gaining of adulthood as a magical, instantaneous transformation, arguing that "[i]t is surely better to think of children as gradually becoming agents while they are still children, with some of their agency spent on what sorts of people they are, and being responsible for this and other actions except when they have excuses for having done badly." (Richards 2010: 176, see also 183-200, and Archard 1993, 58-69). For relevant psychological literature, see Colby and Kohlberg (1987); Kohlberg and Gilligan (1971); Colby et al. (1983). I am grateful to Tommy Peto for guidance on this literature.
} 
are responsible for their choices, their parents' avoidable actions made it much more likely that they acted in a way that they now believe was wrongful between $T_{1}$ and $T_{2}$. The parents are not to blame for the child's actions between $\mathrm{T}_{1}$ and $\mathrm{T}_{2}$ in the same way as the child if the child could have, without parental sanction, refused to eat meat in this period but failed to do so. Post $T_{1}$ the child bears moral responsibility for their actions. The thought, however, is that the child can blame the parents for the situation they found themselves in, whereby they were exposed to moral risk in a way they would not have been had their parents brought them up on a diet whereby not eating meat was their default option. We can characterise the parents' actions as having had, from the child's perspective, a corrupting effect upon the child, by compromising their moral integrity. Consider, for example, the following definition of moral corruption:

[A]corrupt action is a one-off action, or an element of a pattern of actions, that contributes to the despoiling of the moral character of a person, and/or to the undermining of a morally legitimate institutional process, role or condition. (Miller et al. 2005: 5).

The despoiling of moral character is key here. The child believes they have done wrong, and that their life would have gone better from a moral point of view had they acted differently. Whether this means that the child has in fact been corrupted can be left as an open question. One perspective would hold that an individual is indeed morally corrupted when their moral character is despoiled according to their own assessment; another would hold that this only occurs when that perspective is in fact correct, by reference to some account of moral truth. The key for the purposes of this article is that either way, from the child's perspective, their moral integrity has been compromised. Critically, the argument is advanced independently of the claim that eating meat is morally wrong. The child believes that they did wrong between $T_{1}$ and $\mathrm{T}_{2}$, in a way that cannot now be righted, even if they adopt a vegetarian diet henceforth. ${ }^{9}$

Second, we can imagine someone who concludes after $\mathrm{T}_{1}$ that eating meat is morally wrong, but who nonetheless continues to eat meat, and so does not actually become a vegetarian despite endorsing the moral principle behind ethical vegetarianism, because they find it too hard to give up eating meat. This seems far from an unusual position: it is common to find people who accept that eating meat is wrong, but who nonetheless describe themselves as unable or unwilling to give up meat because they enjoy it so much. ${ }^{10}$ The sense in which such individuals should believe that their parents' avoidable actions have corrupted their moral

\footnotetext{
${ }^{9}$ The earlier distinction between ethical vegetarianism and environmental vegetarianism becomes relevant at this point of the argument, as there is something unrectifiable about the moral wrongdoing between $\mathrm{T}_{1}$ and $\mathrm{T}_{2}$ from the perspective of ethical vegetarianism which does not apply to its environmental counterpart. If one locates the wrong of meat eating in the environmental impact of the meat industry, then there are steps that one can take to offset or cancel out the harm to which one's earlier actions contributed. One could, for example, calculate one's lifetime carbon footprint, and make sacrifices in the future in response to one's excessive actions in the past. It is not clear that balancing of this kind is available to the ethical vegetarian. Even if she does a great deal to benefit animals in the future, and even if we accept that animal welfare can be aggregated in a way that human welfare cannot due to the separateness of persons, there is still something unrectifiable about the past consumption of meat. There is also arguably a relevant disanalogy here between not eating meat for moral and for at least some religious reasons, insofar as we believe that dietary restrictions are specifically directed to believers and may in some cases be primarily of cultural or symbolic importance, rather than representing universal moral prohibitions. ${ }^{10}$ Certainly there are significant numbers who are sympathetic to vegetarianism in general despite eating meat: a 2016 YouGov survey in the UK on attitudes to vegetarianism found, in addition to $7 \%$ of adults who described themselves as vegetarian or vegan, a further $7 \%$ who agreed with the statement 'I'd like to be a vegetarian but I'd find it hard", and another 9\% who agreed that "It's a good idea and I'm trying harder to cut out meat" (https:// yougov.co.uk/topics/lifestyle/survey-results/daily/2016/05/18/982f0/1)
} 
character is more straightforward, and given the existence of an ongoing gap between their moral judgments and actions, it seems as if a charge that their moral character has been despoiled (as opposed to the more limited claim that they believe their moral character has been despoiled) can be advanced independently of whether we believe eating meat is wrong. Their parents' avoidable actions have likely resulted in a situation where there is a gap between the child's sense of duty and their actions. Had they not been habituated to eating meat, they would have not been in the position of having to give up something which gave them pleasure, and their moral integrity would likely not have been compromised.

\section{Robots and Parental Fiduciary Responsibility}

The argument thus far holds that children can come to believe that their moral character has been despoiled, in part on account of the avoidable actions of their parents. In the absence of a substantive claim that eating meat is wrong, this does not yet establish the claim that the parents have acted wrongly. This would not even be straightforwardly the case if we believed that the children had in fact been corrupted, as one can readily think of cases whereby an individual might act in a way such that their actions have a corrupting effect according to the definition cited in section (3), but where we believe that they acted legitimately and did not violate any duty to the agent who went on to act wrongly. I might buy an expensive painting from a struggling artist, who might spend the payment on addictive drugs. My winning money from a gambler in a casino might result in the gambler holding up a convenience store at gunpoint to recoup their losses. I might style my hair in a particularly devastating fashion causing someone to fall in love with me and abandon their partner and children. The fact that an action has a corrupting effect on another agent is not sufficient to ground the claim that it is wrong to perform the action in question. This is not to make the stronger claim that actions cannot be wrongful on account of their corrupting effects. Clearly, we can think of cases where someone deliberately sets out to provoke another into acting wrongfully where it is clear that the provoker is guilty of wrongdoing, even if this judgement does not exculpate the provokee. (Think, for example, of the discomfort we sometimes feel at the use of techniques of entrapment by newspapers and law enforcement agencies.) But the identification of a causal link between one agent's actions and another's wrongdoing is not sufficient to establish wrongdoing on the part of the former agent, far less that of a link between one agent's actions and another agent's perception that they have acted wrongfully. However, there is good reason to think that relations between parents and children constitute a special case, where parents possess particular responsibilities in relation to the moral integrity of their children. Harry Brighouse and Adam Swift outline four reasons why the relationships that adults have with the children they parent have a different moral quality from other relationships. The first three are familiar and straightforward: grounded in the unequal power relations between adults and children; the fact that children lack the power to leave relationships with their primary caretakers; and the particular quality of child-parent intimacy. The fourth, however, stems directly from the morally-charged duty of care that parents possess in relation both to the welfare and long-term development of their children. "The parent's fiduciary obligations", they write, "are to guarantee the child's immediate well-being and to oversee and ensure her cognitive, emotional, physical, and moral development." (Brighouse and Swift 2006: 92-4; see also Richards 2010: 164-182.) Parenthood is, to use Ronald Dworkin's phrase, "pregnant of obligation" (Dworkin 1986: 206). In at least those instances where parental care 
responsibilities arise from individuals' voluntarily undertaken actions, these obligations are weighty and significant. Parents owe their children not only short-term shelter and sustenance, but sustained care and concern as they grow and mature. They have to do what they can to help them to grow into flourishing adults. These obligations are not limitless, and parents are entitled to have due regard for their own interests, but they will also be called upon to sacrifice and compromise their own welfare in various ways in order to care for their children.

My claim is that parents violate their fiduciary obligation for their child's moral development if they avoidably perform actions that risk compromising the child's moral integrity, other than in cases where refraining from such actions would be unduly costly. The idea of the compromising of moral integrity employed here is expansive: it covers not only situations where the child is acknowledged to have acted wrongly, but also at least some where, more simply, the child believes they have acted wrongly. It should be a source of regret to a parent that, from the child's own perspective, her life has not gone as well as it could have done from an ethical point of view as a result of the avoidable actions of the parent. A life of moral integrity is one whereby one lives in accordance with one's values, where one believes that one generally does the right thing, particularly in relation to one's most deeply held moral beliefs. Of course no one is perfect, and failing to live up to one's ideals is a predictable and largely inevitable part of human life. But parents owe their children the best possible chance of reaching moral maturity with a clear conscience, well placed to make their own decisions about right and wrong. ${ }^{11}$

The concern that a parent should exhibit for the ethical integrity of their children means that they should not expose them to predictable and avoidable moral risk by feeding them meat. To illustrate this claim, consider the following example. Imagine a robot. This robot possesses artificial intelligence, and has a moral consciousness and a sense of right and wrong, meaning it can engage in moral reasoning in the same way as a human. Being a robot, however, it has no likes or dislikes, no hobbies or tastes, and no life projects of its own. It is concerned only with fulfilling the task for which it was created: bringing up small children. Imagine that the robot is the primary caretaker for a baby. As it raises the baby, the robot will have to make a series of choices about how best to care for the developing child. The robot, therefore, will have a keen interest in scholarly debates over the ethics of child rearing. It will need to decide how to expose the child to different influences, to choose whether to bring them up within a single, comprehensive conception of the good or to expose them to multiple different conceptions, to determine what to tell them about religion, to decide whether to read them bedtime stories, and so on. The robot is both similar to and different from a conventional parent. Though the robot will presumably think it right to teach the child its own sense of right and wrong and will engage in at least some degree of moral instruction, balancing such teaching with the child's interest in forming their own distinctive worldview, it has no vested interest in encouraging the child to adopt particular ways of living beyond this. It is motivated solely by the best interests of the child, in ways that parents reasonably need not be, as they are also entitled to take their own interests into account.

Should the robot feed meat to the child? My claim is that it should not, even if its own moral sensibility does not suggest that there is anything wrong with humans eating meat. The robot has no reason of its own to want the child to eat meat - it has no desire to share particular meals with the child, no romantic associations with particular food stuffs, it does not have to

$\overline{{ }^{11}}$ For a helpful recent account of the nature of parents' duties relating to the moral development of children, see Cripps (2017). 
worry about the inconvenience of cooking a different kind of food from that to which it is accustomed, and so forth. The robot will instead prioritise the interests of the child, and so be concerned solely for their well-being and development. Given the assumption that the health of the child does not depend upon a diet containing meat, the robot will be concerned with other ways in which not eating meat might affect their well-being: thus they would consider the gastronomic pleasure of meat-eating, the possible inconvenience of having a minority diet, and the possibility of social difficulties that might arise from the fact that the child does not eat meat. (Might they be bullied by other children? Might they be excluded from social gatherings that prominently features meat-eating, such as barbeques? For further discussion, see Hunt (2019a: 275-7). . ${ }^{12}$ To the extent that there are such costs then they belong in the debit column, but it might rightly be doubted just how much utility is really lost by never feeding a child meat. (We should be careful, of course, not to confuse our evaluation of this question with the loss of utility that a meat-eater, who is accustomed to eating meat, undergoes when they become a vegetarian: this is clearly potentially very different.) Possible social costs should of course be taken into consideration, though it should be noted that contemporary acceptance of vegetarianism is much more commonplace than was once the case. ${ }^{13}$ In terms of development, however, the advantage seems to lie squarely with not giving the child meat. There is no significant loss of autonomy in being denied meat until the point at which one is able to make a meaningful choice for oneself, but there is a significant potential downside to meat-eating in terms of moral development.

To be clear, the point is not that the robot should bring up the child as an ethical vegetarian, imposing a particular moral principle on the child. Rather, the claim is simply that the dietary choices which the robot makes for the child should not include meat. This is perfectly consistent with explaining to the child that there is widespread reasonable disagreement about the ethics of meat-eating, about which the child will make their own decisions as they grow older. Accepting that the robot is right to withhold meat from the child is sufficient to ground the claim that parents have a morally significant reason not to feed meat to their children.

Should we endorse a stronger claim that parents have an all-things-considered duty not to feed children meat? To make such an argument we must leave the robot behind and consider the costs that such a duty would impose on meat-eating parents. It should not be denied that there are such costs, and that they will be more weighty in some contexts than others. Parents may have to pay more attention to their children's diets than was previously the case, and may have to learn to cook different dishes. They may have to accept that they will have either need

\footnotetext{
${ }^{12}$ I thank an anonymous reviewer for these examples. Some writers have sought to make a stronger case for the interest in eating meat. For example, in his article "Veganism and Living Well" (2012), Christopher Ciocchetti considers a number of arguments made by "meaningful omnivores", who argue that a certain kind of relationship with animals, which includes killing and eating them, contributes to a meaningful life. Versions of this argument make reference to aesthetics, in terms, for example of the taste of meat (see also Kazez 2018); to the importance of a certain kind of honest engagement with the world, which acknowledges the persistence and inevitability of life and death; and to the role that particular foods play in social identity. If one believed that any or all of these arguments were persuasive, then the child's interest in eating meat would be weightier, though Ciocchetti himself denies (in my view rightly) that this is the case. Of course, there is nothing to prevent a child from choosing to adopt omnivorism for such reasons once they pass the point of moral agency, and it is hard to see how they would have cause for moral regret for not having done so previously.

${ }^{13}$ Following the argument relating to health above, it would be possible for parents with a well-founded fear of social harm or exclusion to advocate a diet that permitted, for example, the occasional consumption of meat with friends or in other social contexts. I am dubious whether such a move would really be necessary in the vast majority of cases. Alvaro expresses doubt that this is a realistic prospect even in relation to veganism $(2019,653-$ 7).
} 
to cook both meat and non-meat dishes at mealtimes, or end up eating less meat themselves. They may feel a sense of distance from their children if their children are eating different food from them, and so may feel pressure to eat the same food as their children, meaning they will forego some pleasure from meat-eating. Some children before the point of moral maturity may insist on eating meat, particularly if they live in cultures where meat-eating is commonplace: denying food to such children may prove difficult or upsetting in practice, and may be both costly in terms of the parent's relationship with the child and of the child's own desire to be in control of their autonomous development. Perhaps there are particular issues relating to parents who work in the farming and meat industries, or are chefs who specialise in meat dishes, and so on and so forth. Many other points could be made here. So arguing in favour of the all-things-considered duty entails accepting that all these costs are not so weighty as to outweigh the force of the pro tanto duty, grounded in the parent's fiduciary obligation for the child's moral development. Two issues arise here. One concerns the weightiness of the interests in question - just what kind of a burden is being placed on parents? The second concerns how we should weigh these interests in relation to the child's moral integrity: should the latter have strict priority, or is it just another factor to be included in the overall calculus? A full resolution of this issue is beyond this paper. We might note that, generally speaking, the idea that parents can be asked to make significant sacrifices for the sake of the most important interests of their children is a familiar one, and also observe that there is at least plausibility to the idea that concerns of moral integrity should have a special weighting when compared to interests grounded in the disutility of inconvenience. As stated, my own view is that most parents who live in circumstances of affluence do in fact have an all-things-considered duty not to feed their children meat, and I would need to believe that there really were significant parental interests of moral significance in play, grounded in basic interests such as autonomy rather than mere preference or convenience, before thinking otherwise. But this observation is independent from the primary claim of this article: that parents have a morally significant reason not to feed meat to their children.

\section{The Purported Particularity of Vegetarianism}

It was previously noted that there is an asymmetry between how an ethical vegetarian views a non-vegetarian, and how a non-vegetarian views an ethical vegetarian. This asymmetry is key to understanding this article's claim that the prospect that one's child may come to be an ethical vegetarian places demands upon parents in a particular way, which differentiates the case in hand from many other instances where a child may believe that their integrity has been violated by the nature of their upbringing. It does seem clear that we should not endorse a general claim that parents should not bring up children in any way that the child could subsequently come to reject, as this would be both overly-demanding and impossible to realise, given the different paths that children might choose to tread. Consider, for example, a deeply religious couple who bring up a child within a specific religious context, which the child subsequently rejects, after the point of moral maturity, in order to become an atheist. ${ }^{14}$ It is true that the child may resent the way in which they were brought up, just as a child that comes to be religious may resent having experienced an atheist upbringing. If the parents inculcated particular beliefs relating to the treatment of others which the child acted upon in a

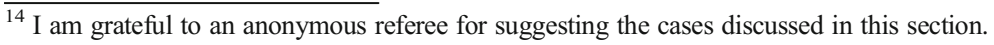


way they now reject, it is even possible that the child might believe that they were avoidably implicated in wrongdoing. Does this mean that the parents act wrongly in raising the child within their faith? Some may believe so, but this is not a consequence of my argument here. The parents in this case may have strong reasons to want their child to follow their faith: perhaps relating to their desire to share important aspects of their lives and identities with their children, and potentially stemming from a desire to inculcate what they view as a correct moral doctrine in their children. They may even believe that doing so is necessary to ensure their children's salvation. These reasons differ from the case of dietary choices in terms of both their character and intensity. The religious parents face a genuine moral dilemma if they have, from their perspective, good reasons both to seek to inculcate religious values in their child but also to allow their child to develop autonomously. In most cases, at least, meat-eating parents do not face a dilemma of a comparable nature. The structure of parental choice is different here: there is no significant moral downside to not giving meat to the child, but at the very least moral risk to the choice involved in feeding them meat.

So my argument applies to a particular context of parental choice: where one approach has a moral downside and the other does not. This marks out dietary choices from a range of other decisions: both those where there are moral aspects to both alternatives facing the parent (such as the choice to enrol a child in a religious faith), and where there are interests in play, but where this moral dimension is missing (such as the decision to require a child to learn a musical instrument). I do want to maintain that dietary choices are relatively unusual in this regard. The likelihood of the child coming to believe that eating meat is wrong, the claim that this belief is reasonable, and the fact that the child becoming an ethical vegetarian will not mean that, from the parent's perspective, the child is engaged in moral wrongdoing even though they may believe that the child has made a mistake about the requirements of morality are relevant to the weight of the reasons that the parent has to withhold meat from their child. But I need not, and would not want to, insist that decisions about diet are necessarily unique in this regard, and am open to the idea that a proper consideration of the fiduciary duties of the parent may have significant implications for how we bring up children, if other cases can be said to have the same kind of structure as feeding meat. One possible instance relates to cases in which parents spend money in ways that confer benefits upon their children, which cannot be easily rejected prior to (and perhaps after) the point of moral maturity. It is certainly possible that children might come to believe that this expenditure is immoral, whilst parents might believe that they are doing nothing wrong, particularly in cases where the effect of the expenditure is to confer competitive advantages on the children. An obvious example would be a decision to pay for private schooling. A child might come to believe that such a form of education is unjust and that they were complicit in taking immoral advantage of others: indeed, one could imagine a situation whereby the child believes this to be the case after the point of moral maturity but whilst still a pupil at the school in question, decides that strictly speaking they should seek to withdraw and instead enrol in a state funded school, but do not do so. This raises some of the same issues as the dietary case, but it does not have quite the same structure. It is plausible to think that the parent believes that the child has significant interests in play (presumably these interests are the point of paying for the education in the first place), and that the child would therefore be significantly worse off were they not to attend the school. This is not to say, of course, that such a decision is indeed justifiable, given the impact of private education on others, even if we accept that the child's interests are in fact in play in the way the parent believes (see Swift 2003). It would, however, follow from the general character of the argument above that the fact that the child might reasonably come to believe that the 
expenditure on their education was immoral, and that they were consequently complicit in moral wrongdoing, is something that the parent should take into account when considering whether it would indeed be justifiable to pay for their education.

A full understanding of the fiduciary duties of parents for the moral development of their children may therefore be action-guiding in cases beyond the dietary realm. The key difference between the meat-eating and the private school cases lies in the significance of the child's interests in play. My claim is that no significant interest of the child is set back if the parent declines to feed them meat. It is this which gives dietary cases their unusual structure. But other consumption related parental decisions, that benefit children but do so while conferring only relatively trivial benefits, do seem to be relevantly similar if children might come to believe (though parents do not) that they contribute to wrongful harm to others. Consider, for example, affluent parents who choose to give their children clothes produced in sweatshops, or who buy non fair-trade goods such as chocolate. ${ }^{15}$ Even if the parents believe that purchasing such goods is justifiable, it is clear that children could come to reject this, and regret their prior complicity with such practices. I do believe that meat-eating is at least distinctive in terms of the threat it poses to children's integrity, but it does not follow from this that it is necessarily unique.

\section{Vegetarianism and Veganism}

One final objection needs to be confronted before concluding. The argument to date has drawn a particular line between meat and other food, suggesting that the possibility of a child adopting the moral principle behind ethical vegetarianism in the future is plausibly sufficient reason for parents to refrain from feeding them meat. But if this is true for ethical opposition to eating meat, might it not be true for other ethically inspired food choices? In particular, if one accepts that parents should not give meat to their children lest they become vegetarians, does not the same argument also imply that parents should not give dairy foods, eggs, or any other animal products to their children lest they become vegans and come to believe that their moral integrity has been compromised?

There is a real issue relating to veganism here, which the article cannot dodge. One could certainly use the argumentation of the article to argue for a similar position in relation to moral integrity and veganism, given the very real animal suffering and death that is caused by the dairy and egg industry, in particular. This being the case, I do in fact think that a version of the central claim of this article, that parents have a morally significant reason not to feed meat to their children, can be fairly straightforwardly extended to all animal products, and certainly to all animal products whose production causes harm to animals. There does seem to be something arbitrary about drawing a line between meat, understood as animal flesh, and at least some other animal products: indeed we might worry that doing so might misrepresent the harm caused to animals by the modern farming industry (given, for example, the relative suffering of layer hens and beef cattle). ${ }^{16}$

Suppose we accept that there is indeed at least a prima facie duty for parents to refrain from feeding their children any animal products. Quite how such a duty translates into all-things-considered action depends upon how we weigh up the aforementioned interests of

\footnotetext{
${ }^{15} \mathrm{I}$ am grateful to an anonymous referee for these examples.

${ }^{16} \mathrm{I}$ am grateful to an anonymous referee for this point.
} 
both parents and children that are at stake. Many parents, I think, would have greater concerns about the risks, costs, and trade-offs associated with veganism than with vegetarianism. The contemporary social contexts within which vegetarianism and veganism operate do make a difference. There are fewer vegans than vegetarians in society, so it is appears less likely that a given child will choose to become a vegan than a vegetarian. Bringing up children on vegan diets is, at least for now, more demanding for both parents and children: more foods must now be avoided, more alternatives found, the potential social costs both within and outside the family are greater. Most significantly, as previously noted, there is a body of literature that argues that feeding children a vegan diet specifically does pose a risk to their health and development (Hunt 2019a, though see also Alvaro 2019). It was previously noted that if one believed that a vegetarian diet was risky for children's health, the appropriate response would be to feed children only as much meat as was necessary to ensure their well-being. It seems that a similar conclusion follows relating to animal products in general: if parents are well-placed to provide plant-based diets to their children without unacceptable risk or cost they should do so. Insofar as this is not the case, they should make the diet as plant-based as is practical and desirable, and reduce animal products as much as possible. ${ }^{17}$ My own sense, although I accept that this is controversial, is that committing to feeding children a vegetarian diet that falls short of veganism represents a practical compromise in this context. Though not the only eligible option open to parents, it errs on the side of caution in terms of the child's health without placing excessive demands on any party. It may well be, however, that strictly speaking scrupulous parents should go further, and strike a different balance that involves fewer or different animal products than is typically the case for standard vegetarian diets.

\section{Conclusion}

The position outlined in this article is contentious and unusual: it currently has little or no real-world presence; it suggests that there are people who are acting wrongly despite not being conscious of doing anything of the sort, who will understandably be indignant at the nature of my claims; and it rests on line drawing and a weighing up of costs which, I have accepted, reasonable people may do differently. It will not convince everyone. It might be worth making clear, this being the case, that this argument is not put forward in a spirit of philosophical game-playing, of trying to tease an argument out as far as it will go, or of trying to make an original argument for the sake of it. My claims here are supposed to be action-guiding: I believe that the claim that parents should not feed meat to their children applies to most parents in contemporary affluent societies. The reasons outlined above were those which weighed most heavily with me when my partner and I made choices about the food we feed to our own children. As noted, the argument is grounded in the fiduciary obligation parents possess to care for the moral development of their children, and does not rest upon an empirical claim that there is a widespread phenomenon whereby children who are fed meat as children and then come to see meat-eating as being morally wrong blame their parents for their predicament. But perhaps there should be such a phenomenon - perhaps, given that we live in societies which have often historically assigned parents quasi-ownership rights over their children, we are too quick to afford rights and liberties to parents, and not pay sufficient attention to the rights and interests of children. Perhaps future perspectives on this matter will be different. Opinion poll

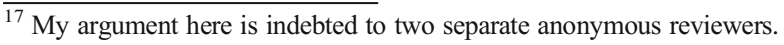


data concerning levels of vegetarianism within the general public is a little inconclusive, but there does seem to be evidence that, in some countries at least, the rate of vegetarianism is growing appreciably among young children and adults. (Radak 2014: 282) As concern for the environmental costs of meat production grows in a context of anthropogenic climate change, and indeed as the technology of artificial meat production develops, more and more people are likely to come into the broad vegetarian fold, and it may well be that this will also lead increasing numbers of people to endorse the claims of ethical vegetarianism specifically. The future world in which current young children and those as yet unborn will live may see significantly increased levels of vegetarianism. For those making choices about how to feed babies from birth, it is this future society which is relevant for assessing the context in which their children will develop their moral agency. The more that non-meat eating becomes mainstream or even normal, the more potential regret there will be for individuals who were involved or implicated in actions which they now believe to be morally wrong on account of the avoidable actions of their parents. This possibility should afford modern day parents, and future parents to be, food for thought.

Acknowledgements I am grateful to audiences at the University of Manchester, the University of Edinburgh, the Centre for the Study of Social Justice, Oxford, and Balliol College, Oxford, and all others with whom I have discussed the themes of this paper, for their comments. I would particularly like to thank Francesca Galligan, Yukinori Iwaki, Dean Redfearn, Patrick Tomlin, and the anonymous referees for Ethical Theory and Moral Practice for their extremely helpful suggestions.

Open Access This article is licensed under a Creative Commons Attribution 4.0 International License, which permits use, sharing, adaptation, distribution and reproduction in any medium or format, as long as you give appropriate credit to the original author(s) and the source, provide a link to the Creative Commons licence, and indicate if changes were made. The images or other third party material in this article are included in the article's Creative Commons licence, unless indicated otherwise in a credit line to the material. If material is not included in the article's Creative Commons licence and your intended use is not permitted by statutory regulation or exceeds the permitted use, you will need to obtain permission directly from the copyright holder. To view a copy of this licence, visit http://creativecommons.org/licenses/by/4.0/.

\section{References}

Alvaro C (2019) Veganism and children: a response to Marcus William Hunt. J Agric Environ Ethics 32:647661

Alvaro C (2020) Vegan parents and children: zero parental compromise. Ethics Educ 15:476-498

Amit M (2010) Vegetarian diets in children and adolescents. Paediatr Child Health 15:303-308

Archard D (1993) Children: rights and childhood. Routledge, London

Brighouse H, Swift A (2006) Parents' rights and the value of the family. Ethics 94:80-108

Bruckner DW (2016) Strict vegetarianism is Immoral. In: Bramble B, Fischer B (eds) The moral complexities of eating meat. Oxford University Press, New York, pp 30-47

Ciocchetti C (2012) Veganism and living well. J Agric Environ Ethics 25:405-417

Clayton M (2006) Justice and legitimacy in upbringing. Oxford University Press, Oxford

Colby A, Kohlberg L (1987) The measurement of moral judgment / Vol.2, Standard Issue Scoring Manual. Cambridge University Press, Cambridge

Colby A, Kohlberg L, Gibbs J, Lieberman M, Fischer K, Saltzstein HD (1983) A longitudinal study of moral judgment. Monogr Soc Res Child Dev 48:1-124

Cripps E (2017) III - Justice, integrity and moral community: do parents owe it to their children to bring them up as good global climate citizens? Proc Aristot Soc 117:41-59

Dworkin R (1986) Law's empire. Harvard University Press, Cambridge 
Feinberg J (1980) A child's right to an open future. In: Aiken W, LaFollette H (eds) Whose Child? Parental rights, parental authority and state power. Adams, and Co., Totowa, NJ: Littlefield, pp 124-153

George KP (1990) So animal a human ..., or the moral relevance of being an omnivore. J Agric Ethics 3:172-186

George KP (2000) Animal, vegetable, or woman?: A feminist critique of ethical vegetarianism. State University of New York Press, New York

Gorczyca D (2017) Nutritional status of vegetarian children. In: Mariotti F (ed) Vegetarian and plant-based diets in health and disease prevention. Academic Press, London, pp 529-547

Hunt E (2016) Parents who feed children vegan diet face prosecution under proposed Italian law. The Guardian 10/8/2016 https://www.theguardian.com/lifeandstyle/2016/aug/10/parents-children-vegan-diet-prosecuteditalian-law. Accessed 20/7/2021

Hunt MW (2019a) Veganism and children: physical and social well-being. J Agric Environ Ethics 32:269-291

Hunt MW (2019b) Parental compromise. Crit Rev Int Soc Polit Philos:1-21

Hunt MW (2021) A defence of parental compromise concerning veganism. Ethics Educ:1-14

Italian court tells veggie Mum: feed your son meat (2015) The Local 28/5/2015 https://www.thelocal.it/ 20150528/italian-court-orders-mum-to-feed-child-meat; original article at http://www.ecodibergamo.it/ stories/Cronaca/che-cibo-al-figlio-genitori-in-disaccordolalimentazione-decisa-dal-tribunale_1123064_11/. Accessed 20/7/2021

Kazez J (2018) The taste question in animal ethics. J Appl Philos 35:661-674

Kohlberg L, Gilligan C (1971) The adolescent as a philosopher: the discovery of the self in a Postconventional world. Daedalus 100:1051-1086

Lucas S (2005) A defense of the feminist-vegetarian connection. Hypatia 20:150-177

Mason A (2000) Community, solidarity and belonging: levels of community and their normative significance. Cambridge University Press, Cambridge

McMichael AJ, Powles JW, Butler CD, Uauy R (2007) Food, livestock production, energy, climate change, and health. Lancet 370:1253-1263

Milburn J (2020) Should vegans compromise? Crit Rev Int Soc Pol Phil:1-13

Milburn J (2021) Zero-compromise veganism. Ethics Educ:1-17

Miller S, Roberts P, Spence E (2005) Corruption and anti-corruption: an applied philosophical approach. Pearson Prentice Hall, Upper Saddle River, NJ

Mills C (2003) The Child's right to an open future? J Soc Philos 34:499-509

Office for National Statistics (2017) Sexual Orientation, UK: 2017: https://www.ons.gov.uk/ peoplepopulationandcommunity/culturalidentity/sexuality/bulletins/sexualidentityuk/2017

Radak T (2014) Vegetarianism. In: Edelstein S (ed) Food science: an ecological approach. Jones and Bartlett Learning, Burlington MA, pp 277-304

Reinart RJ (2018) Snapshot: Few Americans Vegetarian or Vegan, Gallup Well-Being 1/8/2018, available at https://news.gallup.com/poll/238328/snapshot-few-americans-vegetarian-vegan.aspx. Accessed 20/7/2021

Richards N (2010) The ethics of parenthood. Oxford University Press, Oxford

Sherratt A (2007) Vegetarians and their children. J Appl Philos 24:425-434

Swift A (2003) How not to be a hypocrite: school choice for the morally perplexed. Routledge, London

Zangwill N (2021) Our moral duty to eat meat. J Am Philos Assoc:1-17. https://doi.org/10.1017/apa.2020.21

Publisher's Note Springer Nature remains neutral with regard to jurisdictional claims in published maps and institutional affiliations. 